\title{
IMPROVING ENGLISH IMPLICIT GRAMMAR KNOWLEDGE USING SEMANTICO- SYNTACTIC TRANSLATION PRACTICE
}

\author{
Futuh Handoyo \\ (sembloh1@yahoo.com) \\ Politeknik Negeri Malang, Indonesia
}

\begin{abstract}
The present was to respond to the students' low implicit grammar knowledge and, therefore, was concerned with its improvement. The subjects of the study were twenty six students of the first semester accounting students of State Polytechnic of Malang. The strategy used was semantico-syntactic translation practice, which proceeded through three main stages: upgrading their explicit grammar knowledge followed by internalizing the knowledge into explicit grammar knowledge, and testing the result. The result showed that the determined goal was reached in fifteen meetings within one cycle with some extra meetings for oral internalization practice.
\end{abstract}

Key words: implicit grammar knowledge, Semantico-Syntactic Translation Practice

Although the role of grammar teaching has been downplayed and even considered detrimental since Krashen introduced 'zero grammar' approach in language teaching, it has been revived recently. People have begun to realize that grammar is too important to be ignored and that without a good grammar knowledge, learners' language development will be severely constrained (Richard and Renandya, 2002).

Language syllabi neglecting grammar instruction tend to produce learners with low level of accuracy (Sugiharto, 2005). It can be a very serious weakness when the accuracy is so low that it also suffers from low acceptability of pidgin-like language. In addition, Thornburry (2001) reported that some studies 
suggested that learners who received no grammar instruction seemed to be at risk of fossilizing sooner than those who did not. When fossilization occurs, learners' language tends to cease growing in spite of the input exposed to the learners as they are deprived of the capacity to process language input into intake for further process of language acquisition. When this happens too prematurely, they will tend to produce a kind of idiosyncratic language which is much closer to their L1 than the learned L2. Besides the role for language input processing, grammar competence is also important for language output processing. Thornburry (2001) views grammar also serves as a kind of 'sentencemaking machine' as it constitutes a description of the regularities in language that can provide the learners with the means to generate a potentially enormous number of original sentences. That is why it is quite understandable when $\mathrm{Nu}-$ nan (1991) says: "No one seriously interested in the learners do not need to master the grammatical system of the target language: the debate has been over how learners can best acquire the target grammar."

However, it is very likely that the intended target grammar is implicit grammar, instead of explicit grammar. Ellis (2005) says that it is implicit grammar knowledge that underlies the ability to communicate fluently and confidently in L2 and, therefore, it is this sort of knowledge that should be the ultimate goal of any instructional program.

In spite of its important role, English grammar instruction for the Accounting students of State Polytechnic Malang, and very likely the grammar instruction in many schools in Indonesia, from which the Accounting students graduated, has been far from success. Their communicative performance indicates that they have very low implicit grammar knowledge. In general, they demonstrate the ability to communicate only at very rudimentary level, relying heavily on limited number of memorized, not rule-based, formulaic speech they got from language input exposed to them. When the communication requires creative or transferring ability, they tend to activate their Indonesian grammar to string English words into sentences so that their language sounds somewhat like Indonesian grammar wrapped in English vocabulary. They use word for word translation as communicative strategy.

In addition, the four-hour English grammar lesson, two hours in semester one and the other two in semester two, so far has not seemed to work successfully. Feedback from the grammar lessons indicates that the students still fail to significantly improve even their explicit grammar, let alone implicit grammar. 
All the teachers teaching grammar were disappointed with the result of their own teaching. The common report from their own classroom observation was that mostly the students could get scores for the tests on single topics but failed for the tests on accumulated topics. They seemed to learn a segment of grammar and forgot it once they had to learn another segment, so they never accomplished sufficient grammar knowledge and internalized the knowledge. Consequently, grammar lesson always failed to help learners to develop the ability to activate the linguistic features they learned to generate sentences in communicative activities.

From the above discussion, two problems were identified, namely: the students' low grammar competence and their idiosyncratic communicative strategy. In this study, the two problems are seen as mutually related and used as its thematic concern. Low grammar competence will make the learners tempted to activate their L1 grammar to organize L2 data and this will, in turn, block them from the compelling need to improve their L2 grammar because however ill the language they produce, their friends, who have the same L1, still can understand. To respond to the problem, the study focuses on the improvement of both. First, the students' grammar competence is to be improved by upgrading their explicit knowledge and then internalizing the knowledge into implicit knowledge. Second, their communicative strategy is to be altered from word-for-word translation to meaning-to-form or sense-to-form translation. The word-for-word translation is a problem since it has been widely known that grammar across languages does not have one-to-one correspondence. It is even worse because the Indonesian sentences they process are not always standard Indonesian sentences but spoken Indonesian sentences they are likely to use in everyday communication. Therefore, their translation mode needs to be altered in such away that they no longer translate surface-structured Indonesian sentences directly into English sentences. Instead, first they translate the various styles of Indonesian sentences into meaning, and then translate the meaning into standard grammatical English sentences. For example, they are expected to translate Indonesian sentences such as, Mengapa kamu di sini?, Kamu di sini ngapain?, Ngapain kamu di sini etc. into only Why are you here. Focusing on L1 sense out of various form styles is intended to prevent the students from addressing their attention to $\mathrm{L} 1$ forms, and lead them to concentrate on L1 sense, while focusing on L2 standard style is done for the purpose of 
safe use. In this study, such kind of translation is referred to as semanticosyntactic translation.

The main objective of the study, thus, was to improve the students' implicit grammar knowledge using the strategy of altering their mode of translation from word for word translation into L1 sense to L2 form translation. To reach the objective of the study, the research problem was formulated as: How can the students' implicit grammar knowledge be improved using semanticosyntactic translation practice?

\section{METHOD}

The research design used was classroom action research (CAR), which involves a spiral of interlocking cycles of planning, implementing, observing, and reflecting. One cycle consisted of several meetings, which actually also constituted 'cycles' in that each single meeting was planned, implemented, observed and reflected. They then proceeded in spiral direction where the previous meetings determined the details of the later meetings, or the later meetings were always bound to the previous ones. The meetings constitute cycles within cycle, with the whole cycle referred to as main cycle, while the 'cycles' within cycle as sub cycles. The main cycle could be extended at most until the end of the semester, and when the criteria of success were not met by then, the cycle should end and reflection on the whole cycle was made for a new revised cycle for the following year.

The subjects were one class of twenty six students of the first semester of the Accounting students of State Polytechnic of Malang. The topics to cover were Verbs Be vs. Full Verbs, Modal Auxiliary, Negative, Yes-No Questions, and Wh-Questions. The instrument used to measure subconscious grammar competence was timed test, in which the students had to do the task under limited time pressure to demonstrate their spontaneity. The improvement of the competence was indicated by the improvement in the speed and the accuracy of their performance. Then, the research was said to be successful when the subjects' implicit grammar competence improved to such a degree that 60 percent of the students were able to orally translate Indonesian sentences, short dialogue, and short text into English at least $70 \%$ accurate with the speed of $70 \%$ of the speed of formal speech, counted in w.p.m (words per minute). Approximation was used to determine the speed of formal speech by asking three Eng- 
lish teachers to simulate delivering speech by orally translating the tested items. Their speed was counted and the average w.p.m was taken as a parameter.

In this stage, the activity was only focused to design the general procedure of instruction. Learning scenarios for each meeting were designed along the process of implementation as they should unfold in such a way that the later scenarios were bound to the previous ones.

There were three main stages in the instruction procedures: upgrading explicit grammar knowledge, internalizing the knowledge into implicit grammar knowledge, and testing the goal attainment.

During the first stage, all efforts were directed to ensure that the students had explicit grammar knowledge for all topics. For this purpose, every learning scenario for a single topic was implemented, observed, and reflected thoroughly to make the teacher sure the students were ready for the next topic. The main activities were material presentation by the teacher to upgrade the students' understanding on the given topic and followed with written practice, intended to reinforce it. Most of the activities done by the students were translating Indonesian sentences written on a piece of paper into written English. The scores collected from their performance in this stage were treated as formative data and, hence, were only analyzed to determine whether they could continue to the following topic in the next meeting or not. The teacher made intuitive judgment on this, taking into accounts related factors such as kinds of deviations and how much the topic functions as the prerequisite for the next topic.

During the second stage, all activities were focused on making the teacher sure that the technique worked. The process could go through a series of inductive hypothesis testing in order to come to a practice of a good form. The main activities were students' translating meaning expressed in various styles of Indonesian sentences into Standard English. What makes it different from the practice in the preceding stage was that in the previous stage the students were translating written materials, while in this stage, they were spontaneously translating sentences read to them by the teacher with gradually increased speed along the stage The scores of their performance of the first meeting in this stage were used as a baseline to be compared with their scores of the fourth meeting to see whether or not the technique worked. For the sake of reliability, the material for the fourth meeting, which was used for testing, was the same as the material for the first meeting. When the technique worked the process continued to the last stage, namely the stage of testing. Otherwise, the practice was 
modified gradually until it worked. Similar test were given every other meeting with the preceding scores became the base line to the following scores.

Finally, in the third stage, the activity was recording the students' performance. Attention was focused to monitor whether the goal was achieved or not. When the data showed the goal was achieved, the research was declared to succeed and could come to an end. Otherwise, further internalization practices were given and this stage constituted a stage of a series of practice and test activities.

\section{FINDINGS}

Description of the Implementation Process, the Collected Data, and Their Analysis

The implementation of the instructional procedure began by elaborating the procedure of the instruction into learning scenarios leading to the achievement of the goal. The learning scenarios were not designed in one time but in succession with the feedbacks from the implementation of a learning scenario for the previous meetings determined the details of the learning scenarios for the following meetings. The cyclic process unfolded spirally throughout the whole stages of instruction.

\section{First Stage}

The first seven meetings were required to complete this stage. The scores collected from their performance in this stage were treated as formative data and, hence, were only analyzed to determine whether they could continue to the following topic in the next meeting or not. Of all the topics under study, only the first topic, Be and Full verbs, needed an extra meeting. The reason was the teacher considered the topic so basic and would underlie all the following topics and he intuitively judged that the students' performance reflected from their scores in that first meeting was not enough. 


\section{Second Stage}

The next four meetings were used for internalizing the students' explicit grammar knowledge. The scores of their performance of the first meeting in this stage were used as a baseline to be compared with their scores of the fourth meeting to see whether or not the technique worked. The result showed that out of 26 students, 23 increased, 2 decreased, and 1 leveled. The mean of their scores also increased significantly from 59.26 to 77.88, with the t value of 5.386 significant at the level of .0005 (one tailed), which was much higher than the critical value of 3.725. The figures convinced the teacher that he could use the technique to improve the students' implicit grammar knowledge. Therefore, the process continued to the next stage, namely measuring the position of the students' performance against the criteria of the goal attainment.

\section{Third Stage}

In the first meeting of the testing stage, the students were to orally translate written materials in the form of separate sentences, short dialogue, and short text and were recorded. The result showed that only eleven of them whose accuracy scores were 70 or more, which means that the research was said as not yet successful and needed more meetings for internalization practice. On reflecting the result, the teacher suspected that one of the reasons for not meeting the criteria of success was because the students were not used to practicing orally and he hypothesized that progress obtained through written practice was not automatically transferred to oral practice. Therefore, the next internalization practice was oral translation practice. Two meetings were, then, provided and the central activities were peer works, in which they drilled one after another. In the fourth meeting, recording was done again much like in the first meeting. The materials were not the same but made similar with the materials for the first recording. The result showed that sixteen students managed to get 70 and more. Now the criteria of success for accuracy were met. There was significant increase from the mean of 63.74 in the first recording to 72.07 in the second recording. The t-value was 2.789 significant at the level of .005(one tailed).The $t$ value is slightly higher than the critical $t$ value of 2.787 . 
Concerning the speed, their scores decreased from the mean of 48.73 w.p.m in the first recording to 39.19 w.p.m.in the second recording. However, judged against the speed used as a parameter, which was 35.40 w.p.m, all the students who met the criteria for the accuracy could meet the criteria for speed as well. The slowest speed of the fifteen students was 35.63 w.p.m. Therefore, by the end of the fifteenth meeting, the research was said to succeed. The decrease, as the teacher interpreted, was likely caused by their increasing attempt in activating their learned grammar and deactivating their previously unacceptable implicit grammar. This symptom could even be viewed as a positive trend as it could indicate that they were setting a mechanism of using grammar knowledge to produce sentences or using grammar as a sentence-generating machine.

As a whole, the actual implementation of the instruction was basically the same as the one planned. The difference was only that in actual implementation there was one additional stage, namely, oral internalization, which required some extra meetings.

Table 1. The Students' Scores from the First Recording and the Second Recording

\begin{tabular}{llllll}
\hline No. & $\begin{array}{l}\text { Students' } \\
\text { Initials }\end{array}$ & $\begin{array}{l}\text { Scores of 1 }^{\text {st }} \\
\text { recording }\end{array}$ & $\begin{array}{l}\text { Speed in } \\
\text { w.p.m }\end{array}$ & $\begin{array}{l}\text { Scores of }^{\text {nd }} \\
\text { recording }\end{array}$ & $\begin{array}{l}\text { Speed in } \\
\text { w.p.m }\end{array}$ \\
\hline 1 & AW & $86^{*}$ & 39.24 & $87^{*}$ & 35.63 \\
2 & AH & $86^{*}$ & 56.11 & $75^{*}$ & 39.53 \\
3 & AJP & 42 & 29.51 & 66 & 18.80 \\
4 & AR & $88^{*}$ & 59.08 & $97^{*}$ & 42.50 \\
5 & AGC & $81^{*}$ & 39.05 & $87^{*}$ & 35.63 \\
6 & AS & $81^{*}$ & 62.99 & $90^{*}$ & 57.01 \\
7 & AT & 56 & 56.46 & 69 & 38.08 \\
8 & AHF & $88^{*}$ & 70.21 & $97^{*}$ & 50.13 \\
9 & AK & 58 & 60.75 & 56 & 39.28 \\
10 & CN & 49 & 58.67 & 53 & 39.28 \\
11 & DGN & 56 & 40.09 & 66 & 27.10 \\
12 & DAN & $72 *$ & 52.13 & $72^{*}$ & 42.70 \\
13 & DAD & 51 & 38.92 & $72^{*}$ & 36.91 \\
14 & DP & 63 & 42.48 & $72^{*}$ & 37.45 \\
15 & FY & $84^{*}$ & 56.73 & $90^{*}$ & 53.42 \\
\hline
\end{tabular}




\begin{tabular}{|c|c|c|c|c|c|}
\hline \multicolumn{6}{|c|}{ Table continued } \\
\hline 16 & LW & 86* & 58.01 & 94* & 58.80 \\
\hline 17 & NN & 67 & 49.42 & $78^{*}$ & 37.55 \\
\hline 18 & $\mathrm{NE}$ & 63 & 33.03 & $75^{*}$ & 37.70 \\
\hline 19 & OC & 39 & 29.68 & 62 & 25.51 \\
\hline 20 & RA & 46 & 49.42 & $97 *$ & 41.01 \\
\hline 21 & RS & 44 & 41.12 & 19 & 29.08 \\
\hline 22 & SB & $95 *$ & 66.24 & $94 *$ & 55.32 \\
\hline 23 & SW & 58 & 28.94 & 44 & Get stuck \\
\hline 24 & SR & 2.3 & 27.05 & 40 & 22.78 \\
\hline 25 & $\mathrm{TN}$ & 30 & 50.90 & 28 & 28.86 \\
\hline \multirow[t]{2}{*}{26} & WB & $86^{*}$ & 51.10 & $94 *$ & 49.73 \\
\hline & Mean & 63.74 & 48.73 & 72.07 & 39.19 \\
\hline
\end{tabular}

* passing score

The general actual stages of the implementation can be summarized in the following figure:

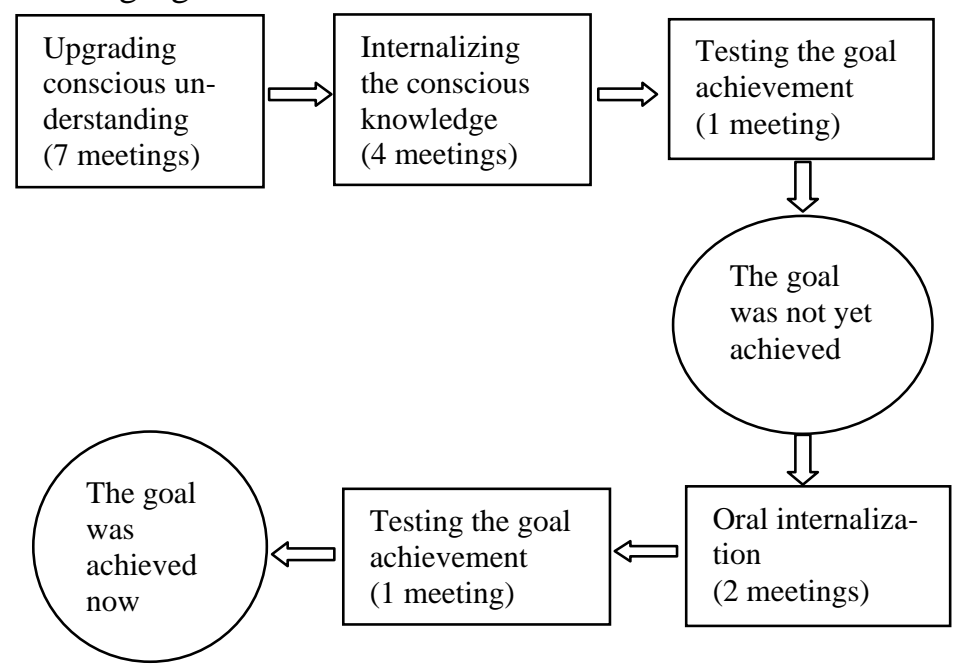

Figure1. The Actual Stages of the Instructional Implementation 


\section{Students' Response to the Use of the Translation Technique}

A questionnaire was distributed to the students with the purpose mainly to explore their opinion and feeling towards the use of the technique. When asked whether or not the use of the technique should be continued for the next semester, out of 26 students, 25 of them said that it should be continued and one wanted a change. When asked whether there was any topic under study which had never been discussed in their previous education level, all the 26 students negated, and when asked whether they got some progress from the activities in this study, 25 said they certainly did and only one said he did not yet. When they should tell what kind of progress they felt they got from the activities, most of them said they felt more confident with the sentences they made and some of them said they could get more vocabularies. One of them stated that with the technique, she no longer needed to study whenever there was a test; unlike what she experienced in the past, which required her to study a lot of materials any time she had a test.

The above information indicated some points. First, most of the students as the subjects of the study had positive attitude toward the use of the translation technique. Second, most of them felt they improved more on their implicit grammar than the conscious grammar. Third, by focusing on grammar problem and allowing the students to ask about difficult words they came across along the process, the students could also enrich their vocabularies peripherally or effortlessly.

\section{Reflection}

Since the goal of the study was already achieved, reflection was done not to design a new revised procedure for a new cycle but to increase its effectiveness for future use. Throughout the main cycle, there were two things worth reflecting upon for this purpose. First, the fact that oral internalization activity was required before the goal attainment suggests that the activity need to be more optimized, for example, by reducing the amount of written internalization. Second, the fact that the job of the students not only involved upgrading conscious grammar knowledge and internalizing the knowledge but also deactivating their previous unacceptable implicit grammar knowledge needs to be taken into account. Teachers need to be more aware that it is a hard job as it is 
concerned with eradicating habit, so they can anticipate by being more patient, more helpful and more understanding.

\section{DISCUSSION}

The result of the study indicates : 1 ). For practical teaching purposes, especially for the context of EFL for adult learners, conscious and subconscious grammar knowledge are better viewed as points of continuum, instead of dichotomies. 2). Translation can constitute a potential and legitimate strategy when done properly.

\section{Convertibility of Explicit into Implicit Grammar}

The fact that with more controlled practice the subjects of the study could improve their spontaneous performance indicate that there is a strengthening effect of repeated practice on how much explicit knowledge is internalized. This supports interfacing position viewing explicit and implicit grammar as points of continuum. At the same time, this also supports unitarian position in cognitive psychology, who sees short term and long term memory in human cognition as points of continuum as well.

For EFL, the view implies the necessity of explicit grammar instruction although the end of the instruction should be on implicit grammar, with explicit grammar only as a means to an end. Since natural communication needs high degree of flow or spontaneity, grammar competence, to be active in communication process, should be internalized to a degree that it is available any time needed for communication. However, it does not automatically mean that to reach the required degree of spontaneity is simply a matter of increasing controlled practice. As observed from the subjects' performance in Speaking class, there was no indication that they automatically activate their grammar competence in communicative task but now they showed better response to corrective feedbacks from the teacher. Besides that, as indicated by Schmidt and Frota ( in Ellis 2001, and Izumi \& Bigelow, 2000), that grammar knowledge will be hardly activated in authentic and natural communication until it is activated in the process of noticing the input exposed to the learners. The conclusion, there-

fore, is there is a need to integrate controlled practice and exposure if grammar knowledge is to function in authentic communication. 
Handoyo, Grammar and Semantico-Syntactic Translation Practice 197

\section{Legitimacy of Translation in EFL}

Translation needs to be considered in foreign language teaching, particularly when learners are still at the early level of proficiency. Learners of early interlanguage stages or beginners still have very limited skill and knowledge about the target language so they tend to use their previous mother tongue as a means to organize the target language data (Brown, 1978). Therefore, in these stages, interference from native language is unavoidable and the learners will transfer their L1 features to their L2, in spite of prohibition whatsoever. The interlingual deviations will diminish gradually as their competence in L2 is increasing. Thus, it is a waste of time telling the early learners not to translate as it is unrealistic and against their instinct. To reduce the problems of interference, learners are not to block them but to go through them. It is likely for this reason why most of the subjects showed positive response to the translation technique used in the study. Beside that, this finding is also consistent with a study conducted by Liao (2006) investigating EFL learners' beliefs about and strategy use of translation in language learning. One of the findings was that non-foreign language majors and less proficient learners tended to report more positive beliefs about translation and more use of translation, compared from foreign language majors and more proficient peers

However, it is necessary to note that translation should not be done on surface structure level of equivalence because grammar across languages does not

have one to one syntactic correspondence. As suggested by Widowson (1987), translation for teaching purposes should be made, at least, to semantic level.

\section{CONCLUSIONS}

Semantico-syntactic translation practice appears to be an effective strategy to develop subconscious grammar competence when carried out through the following procedure.

First, a group of linguistic features to be taught is identified. This constitutes an essential step since the strategy is not designed to use for all linguistic features but only for those that are difficult to acquire naturally or inductively through exposure in communicative activities. Second, the group of linguistic features is then analyzed to determine the sequence for presentation-which is prerequisite for which. Third, the group of the sequenced linguistic features is 
broken down into a number of subgroups, which are estimated to be still within the capacity limit of the students' short-term memory to handle and which enable the teacher to design meaningful practice in the form of simple dialogues and texts. The instruction then is carried out based on the subgroup units, e.g. when the first subgroup is completed, the second subgroup is started. Fourth, the students' explicit understanding on all linguistic features in the first subgroup is upgraded through the following steps: (1) the students' entry behavior on the given topic is identified, (2) the aspects of the linguistic feature beyond the students' entry behavior is presented by the teacher, (3) the students' practice translating messages expressed in various kinds of L1sentences into grammatical L2 in normal speed to reinforce their understanding on the given topic. The three steps were repeated for the other topics until all the topics in the subgroup are covered. Fifth, all the linguistic features in the subgroup are now internalized by the students through the same practice but with gradually increased speed and task difficulty - from written to oral task.

The same process, then, is done to the other subgroups such as summarized in Fig.2.

However, the developed implicit grammar, as observed in the subjects and indicated in some literatures, does not automatically underlie the process of language production for communicative purpose until it is activated in the transitional process of noticing gap. The main function of the subconscious grammar competence, therefore, is to help the students process the knowledge they get from grammar class to a degree that they can use the knowledge later to notice the language exposed to them when they begin their attempt to activate the knowledge in more meaningful communicative activities in reading and speaking class or in other communicative contexts. The ability to activate grammar competence for noticing purpose bears, at least, two important implications. On the one hand, the knowledge they get from grammar class is no longer subject to forgetting and gone but accumulated and used. On the other hand, the language input exposed to them in meaningful communicative contexts can be more optimally turned into intake and processed to enhance further process of acquisition, instead of only leading the students to memorize formulaic speech contained in the exposed input. 
Handoyo, Grammar and Semantico-Syntactic Translation Practice 199

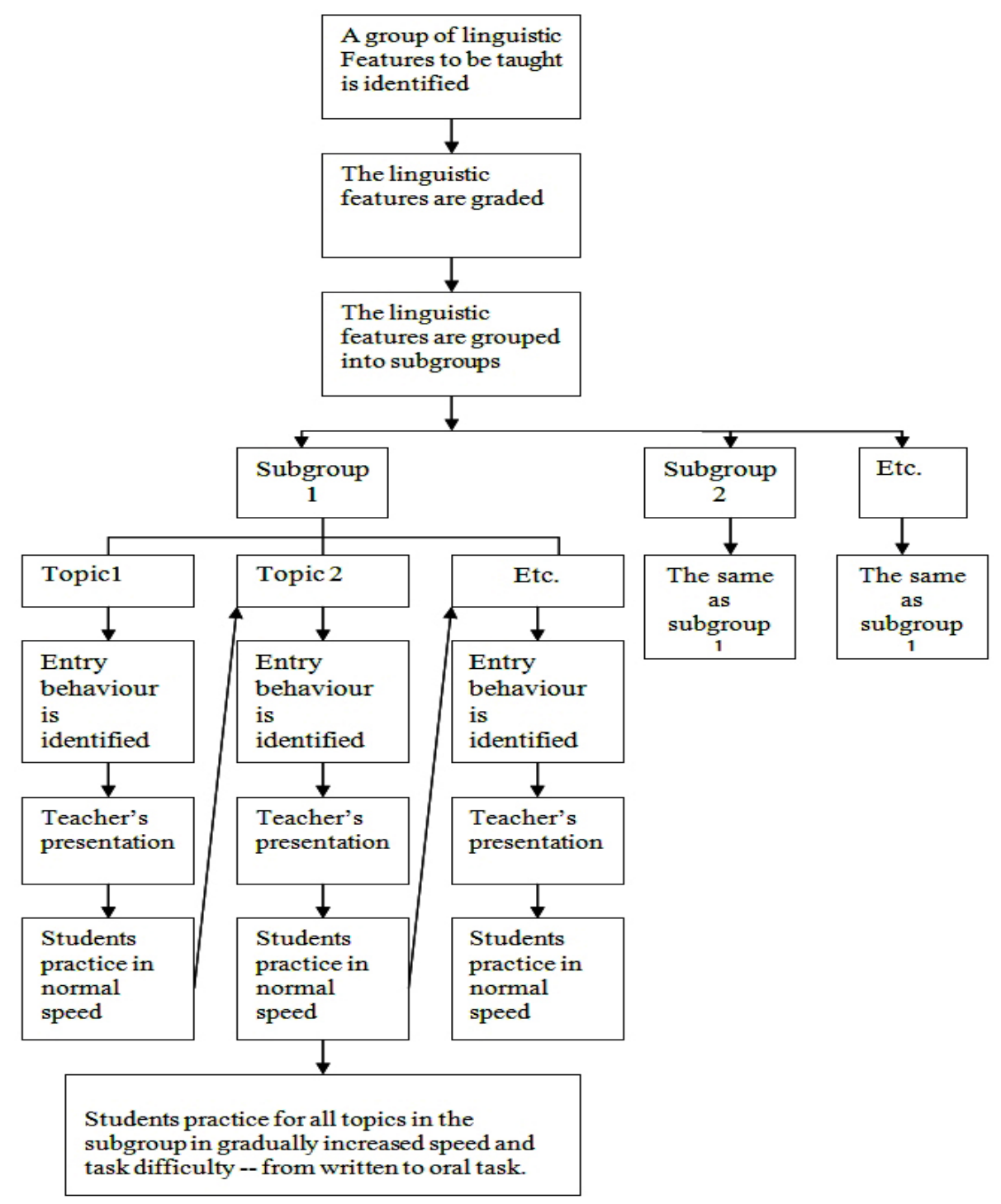

Figure 2. The Procedure of Semantico-Syntactic Translation Strategy 


\section{SUGGESTIONS}

First, to English teachers, it is suggested to realize that the target of grammar instruction is not only students' explicit grammar but it should be internalized into implicit grammar. For this purpose, semantico-syntactic translation strategy can be considered as an alternative. Second, the designers of English curriculum for Secondary Schools and High Schools are suggested to consider including intensive grammar instruction at least to a certain degree so that the students are prepared to operate hypothesis-testing mechanism or noticing mechanism as expected in extensive grammar instruction in the current curriculum. Intensive and extensive grammar instruction should be seen as complementary, rather than alternative, so that they need to be integrated. Finally, to obtain more significant finding for both pedagogic application as well as theory construction, language teaching researchers are suggested to conduct a followup research that seeks to develop subconscious grammar competence to a degree that it can underlie the learners' language in natural and authentic communicative performance. The initial procedure can be designed based on the conclusion drawn in this research, namely, grammar instruction basically consists of two main stages, converting explicit grammar into implicit grammar followed by using the resulted implicit grammar to trigger the act of noticing gap.

\section{REFERENCE}

Brown, H. D. 1987. Principles of Language Learning and Teaching. New Jersey: Prentice Hall, Inc.

Dulay, H. \& Krashen .S. 1982. Language Two. New York: Oxford University Press

Ellis, R. 2001. The Study of Second Language Acquisition. Oxford: Oxford University Press

Ellis, R. 2002. Grammar Teaching-Practice or Consciousness Raising? In Jack C. Richards and Willy A.Renandya (eds),_Methodology in Language Teaching. USA: Cambridge University Press.

Ellis, R. 2004. The Definition and Measurement of L2 Explicit Knowledge. Language Learning Journal Vol. 54, No.2 
Handoyo, Grammar and Semantico-Syntactic Translation Practice 201

Ellis, R. 2005. Principles of Instructed Language Learning. Asean EFL Journal. Vol.7, Issue 3.

Ellis, R. 2006. Current Issues in the Teaching of Grammar: An SLA Perspective. TESOL QUATERLY. Vol. 40. No.1.

Izumi, S. \& Martha, B. 2000. Does Output Promote Noticing and Second Language Acquisition? TESOL QUARTERLY. Vol. 34, No. 2.

Liao, P. 2006. EFL Learners' Beliefs about and Strategy Use of Translation in English Learning. RELC. Vol. 37 (2). London, Thousand Oaks CA and New Delhi: Sage Publication.

Nunan ,D.1991. Language Teaching Methodology. Great Britain: Prentice Hall International (UK) Ltd.

O’Malley, M. J. et al. Some Application of Cognitive Theory to Second Language Acquisition. Retrieved August, 2008 from http://coursestar.org/ku/markham/TL817/docs/O_Malley.htm

Richard, J. C.2002. Methodology in Language Teaching. USA: Cambridge University Press.

Sugiharto, S. 2005. Interpretation-Based Approach to Grammar Teaching: New Directions in Theory and Practice. TEFLIN Journal Vol, 16 No. 2.

Thornburry, S. 2001. How to Teach Grammar. Pearson Education Limited England. 